\title{
Application and Research of Folk Art Elements in Flash Animation ---- Taking Minnan Folk Art as an Example
}

\author{
Weng Zhen \\ School of Digital Creativity, Xiamen University of Technology, Xiamen 361024, China
}

Keywords: Shadow play; Minnan folk art; Flash animation production

\begin{abstract}
Shadow play is one of the characteristics of Chinese Minnan art. It is also one of the earliest operas in China and the earliest shadow art behind the scenes. As a traditional folk art form, in the faster and better development process of shadow play, the cultural and artistic elements contained in shadow play are discovered and applied in contemporary Flash animation. With the development of China's science and technology, animation industry also constantly uses new technologies, but the traditional national art elements in shadow play are the same. Many of China's traditional folk arts have been forgotten with current technology and the evolution of multimedia forms, thus it is very necessary to move traditional Chinese folk arts to the curtain. Shadow art makes Minnan shadow opera folk art rejuvenate in the technology research and development of Flash animation production. Through the elaboration of the artistic expression and artistic characteristics of shadow play, this paper analyzes Flash animation principle, discusses the advantages of Minnan folk shadow play art in Flash animation, and the development future of shadow play art in Flash animation production is forecast.
\end{abstract}

\section{Introduction}

China's folk traditional art is various, which shows different regions' folk art in different folk art forms, containing the feelings of the times, the implication of all things, and all ethnic groups' better life yearning. Minnan shadow art is undoubtedly the most typical folk art in it with strong shape characteristics and full of Minnan people's living atmosphere. It is a more typical form of artistic realization in China's traditional folk art. Shadow play has a strong Minnan folk style and interesting and exaggerated expression way, which people adore. With the renewal of social science and technology, digital technology has brought a revolutionary change to traditional animation production. Paperless digital animation creation technology saves production costs and at the same time saves significant time in production. In particular, the emergence of Flash technology makes cutlery animation simpler. And at the moment traditional shadow art is unable to meet people's fresh art demand, and Flash digital animation technology is very similar to the artistic expression of traditional shadow play. The two can mutually reinforce each other and make common development, and this is indispensable in contemporary society animation production.

\section{The artistic expressions and features of Minnan Art}

\section{A. Shadow play art drawing form}

Shadow play, as one of Minnan folk arts, is also known as "leather shadow play", and people usually call it shadow play. In shadow play performance process, usually the performers are standing behind a white curtain and manipulate the shadow. At the same time, they sing the opera plot in local Minnan language. There are musical instruments commensurate with the show and it is of strong national artistic characteristics [1]. More obvious bright colors, such as red, black, green are often used in shadow play production process. While drawing a variety of characters and natural scenery, we also pay attention. In role production process, we also stress the full of roles: the male lead, the female lead, the painted face and the clown. In production, the general requirements are in $10-60 \mathrm{~cm}$.

\section{B. Shadow play's art production and performance characteristics}

The shadow in shadow play is usually controlled by people through a white line after being 
made by carving, so they can achieve free control effect in shadow play. It usually takes 5 to 6 small bamboo poles for a shadow figure character manipulation, and the length of bamboo pole also needs to change based on the role of each shadow figure. When performing a shadow play, a person usually has to manipulate multiple shadow roles. Shadow play performers are often able to use flexible fingers to vividly show shadow art, which is highly praised. Shadow art performance staff should not only learn flexible manipulation, but also be able to speak, mimic, tease and sing proficiently, and they have to master instruments operation. Shadow art performance cost is low so the popularity is very wide. It is popular with people, so it spreads so far. Now shadow art has been collected around the world and has very high artistic value.

\section{The working principles of Flash animation production technology}

\section{A. Flash software's time-line and frame}

The production concept of Flash animation technology software, at the beginning of design, is not to produce animation. Because of the evolution of society, the concept of time-line and frame in Flash software is more and more widely used in traditional two-dimensional animation production process. When used, the principle is relatively simple and easy to operate, which can greatly improve the production efficiency of animation, so it is increasingly widely used in the production process of animation, and is strongly welcomed in a wide range of users. It is popular in two-dimensional animation field's digital production [2]. Flash animation technology developers are in line with people's spiritual and cultural level requirements in order to comply with the needs of social development, so with continuous upgrading and changing versions in the development process, Flash animation technology's software functions are increasingly powerful.

B. Flash software's tween animation technology

With the wide application of time-line and frame, Flash animation technology software is no different from traditional two-dimensional animation in layer rendering function and frame produced animation concept in the process of making animation. In addition, the biggest feature of Flash animation technology is to generate "tween animation" by the computer itself. "Tween animation" production function can move the uploaded animation picture in accordance with a certain trajectory in the production process. In the specified production path movement process, it can also change the size, color and transparency and other animation attributes of the animation character thus produce ideal animation to meet the visual needs of the audience.

C. Flash technology and shadow play production principle

Flash animation production software's "tween animation" is a major feature of its production process. Other features are animation "components" and "library" design concept. The creator can make the animation role picture as production component with certain attribute in production process, which is automatically saved in the subsequent production process. This will give the future production process great convenience, and you can always requisition this property without repeating the steps. To a large extent, this saves animation production efficiency. It can be seen that Flash animation technology software is animation production software combining a variety of functions from the principle point of view, and the role models in shadow play can be used repeatedly. They are the same principle, but related elements in shadow play are converted into digital information production and two-dimensional animation show is in Flash software.

\section{The advantages of shadow play in Flash animation}

The artistic elements in shadow play are unique in Minnan folk arts, and it is different from other art types. It is widely used in Flash animation software and has good application effect because of the same principle and universality.

\section{A. Plane image representation}

Shadow play is mainly demonstrated in flat image in the process of artistic performance, and the animation produced by Flash software is based on the plane presentation of animation software, which can handle the same location's silhouette image. Shadow is usually the side of the image in 
the process of modeling and the performance scene is also mostly flat, so there is no rich sense and three-dimensional effect. This is difficult to meet people's visual needs. There are mainly mono-color filling and there is not natural changing color and no strict color skills, resulting in no delicate color effect. It is suitable to express with single-sided vector images. It is the plane expression form that gives a direct plane image processing advantages for Flash technology, especially in the use of Flash animation software to create vector graphics image animation. Computer technology can make a more smooth and natural effect for planar image processing, and the picture is more vivid.

\section{B. Tween animation}

Shadow play depends on white curtain to perform, and its artistic expression is very similar to Flash animation production principle. Traditional shadow artists complete the performance behind the white curtain in the process of shadow play performing, making the shadow role to complete a series of actions like flip and move. Through translucent white curtain, use lighting effects to show the audience vivid shadow play. Flash animation production software relies on this expression form and develops software tools such as "tween animation" and "any deformation", making shadow play and Flash animation production form complement each other. This perfectly realizes traditional shadow artists' high performance skills to achieve animation art effect, and it is more vivid and exciting in comparison.

\section{No need for frame-by-frame production}

Shadow play animation production does not need frame-by-frame production, and this feature is one of the advantages of association with Flash animation software. Under normal circumstances, in the process of making two-dimensional animation, in order to pursue smooth animation effect and delicate animation details, frame-by-frame processing tools will be used extensively in animation production, and it is even used for a small amount in the production of paper-cut animation. Although supporting the use of frame skills in animation production, but the artistic characteristics of shadow play decide that it is a more simple production process. Flash software frame-by-frame operation is a time-consuming and complicated work. Eliminating this step, higher animation production efficiency can be achieved and Flash technology "tween animation" tool advantage can get maximum play.

\section{The future development of shadow play in Flash technology}

With the rapid development of society, traditional form of shadow play cannot meet the visual level of people's needs, and traditional shadow play transmission mode is not able to adapt to the development needs of the current social market. But through Flash animation software, shadow play can be innovated in expression form of traditional art so as to spread in a new way, making shadow play, this strong Minnan folk art to carry forward [3].

\section{A. Production and dissemination}

From animation production and artistic expression spread, the use of Flash animation technology changes traditional shadow play production and artistic performances. By the implementation of entire digital animation process, a lot of manpower and material resources are saved, and this at the same time improves the efficiency of animation production. Flash software, after animation completion, can also use computer technology for post-special effects processing, and produce vivid animated digital images. After production completion, it can be played over and over again through a variety of social media playback software, rather than the traditional shadow play form, relying on artificial live performances again and again. In addition, Flash animation production files support SWF format, and such files account for smaller computer space with well curtain visual effect, so smooth animation has become an important part of today's web animation. Through Flash animation technology, shadow play can be better spread and the original artistic tension is expanded.

\section{B. Artistic expression}

Flash animation production technology can provide a lot of room for improvement in production effects, such as shadow play characters, scene modeling, elemental color, lens and other 
aspects. In Flash technology production platform, shadow play characters props and scenes cannot be bound by traditional real material and have a broader imagination in design effect. In the production of animation efficiency, Flash technology can produce animation more easily and is easy to modify the various elements of the animation. In animation background, the background of shadow play relies on lighting and white cloth, which is too monotonous. Flash technology produces background through the use of curtain layering tool in the software to create a vivid animation scene. At the same time, more artistic elements are used to enrich the form of animation. Thus, the application of Flash technology has brought a very broad imagination space for the visual effects of shadow animation.

\section{Soundtrack}

Whether in animation or in shadow play, soundtrack is extremely important. Later music, compared to live music, has a deeper expression form. In addition, usually the audiences are in front of the white curtain to watch traditional shadow play performance and shadow artists are in the back of the show. There is no multi-level depth scene effect. Flash technology gives animation artistic expression lens such as push, pull, shake and move, which opens a new way for shadow play's artistic dissemination.

Author: Weng Zhen (1975.6 -), male, Han, Fujian Putian, master, associate professor, research direction: art and communication.

Fund Project: 2014 High-level Talent Project "The modern transformation and application research of Minnan regional cultural elements in cultural and creative product design" of Xiamen University of Technology (Project number: YSK14005R)

\section{References}

[1] Yan Chunfeng. Development and application of multimedia software ---- Taking Flash animation design software as an example [J]. New Media Research, 2015, 1 (17): 13-14.

[2] Wang Chao. National art elements application in Flash animation image language [J]. Art Education, 2016 (3): 136-136.

[3] Sun Han. Flash animation application in folk art elements [J]. Art Tasting, 2016 (1). 